\title{
Knowledge, Attitudes, Income and Implementation Regarding the Dengue Fever Prevention Program in Medan, Indonesia
}

\author{
Heppy Santhi ${ }^{1}$ Irnawati Marsaulina ${ }^{2}$, Nurmaini ${ }^{3}$ \\ 1,2,3 Faculty of Public Health, Universitas Sumatera Utara, Medan, Indonesia \\ Email: sunshine.first_one@yahoo.com
}

\begin{abstract}
:
The best program to control the spread of dengue infection is a dengue prevention program. Indonesia has a dengue prevention program known as $3 \mathrm{M}$ Plus. Medan City is one of the endemic areas of dengue fever in Indonesia. This study aims to evaluate the knowledge, attitude and income implementation of the dengue prevention program in Medan. Information on sociodemography, knowledge, attitudes, and implementation of dengue prevention was collected using a semistructured questionnaire that had been tested previously. This cross-sectional survey was conducted with face-to-face interviews with 100 randomly selected heads of households. Bivariate analysis using chi-square test. The results showed that overall participants had low family income, poor dengue knowledge, moderate attitude and moderate prevention implementation. There was a significant positive relationship between family income and implementation of dengue prevention $(p=0.001)$, knowledge and implementation of dengue prevention $(p=0.012)$, and attitudes and implementation of dengue prevention $(p<0.001)$. In conclusion, dengue prevention programs require increased knowledge, attitudes and implementation of dengue prevention. Households with an income below the city minimum wage must be the main target of the dengue prevention campaign. Knowledge-based campaigns and arousing positive attitudes will increase the application of dengue prevention.
\end{abstract}

Keywords:

dengue fever; prevention; implementation; programs; $3 M$ Plus

\section{Introduction}

Dengue Hemorrhagic Fever is a viral disease transmitted by mosquitoes that has spread rapidly throughout the tropics and subtropics in the world. It is estimated that more than 50-100 million cases of dengue occur annually throughout the world, with 3 billion people living in dengue endemic countries (WHO, 2016). Health threats and the economic burden of dengue fever have increased substantially. The incidence of DHF worldwide has increased 30 times in the last 50 years. The increase in disease is reported to be close to $75 \%$ of the population exposed to dengue in the Asia-Pacific. (WHO, 2012).

In Indonesia, dengue fever is endemic in all provinces. In 2017 there were 68,407 dengue cases with 493 deaths in Indonesia. North Sumatra is the fourth highest-incidence province, with 5,327 cases and 29 deaths (Ministry of Health of the Republic of Indonesia, 2018). The highest incidence in this province is in Medan City with 1,214 cases and 11 deaths. The incidence rate of dengue fever in Medan is 54.02 per 100,000 population (North Sumatra Province Health Service, 2018). This number exceeds the national target of below 49 per 100,000 population, and the Case Mortality Rate of $0.91 \%$ is close to the national target limit, which is under $1 \%$ (Ministry of Health of the Republic of Indonesia, 2015).

Indonesia has a dengue prevention program known as 3M Plus. The " $3 \mathrm{M}$ " were Menguras (cleaning water containers), Menutup (covering water containers), and Mengubur/Mendaur ulang (burying/recycling discarded items). Meanwhile "Plus" includes all specific activities to reduce 
mosquito breeding and activities to protect human from mosquito bites (Ministry of Health of the Republic of Indonesia, 2016).

A study in Brazil found that dengue is socially more likely to reach populations with low economic status (Johansen et al, 2018). In addition, the higher the level of education, the better the practice of implementing dengue prevention (Causa et al, 2019). A study in Sleman, Indonesia found that community knowledge was at a moderate level, so knowledge needed to be improved, focusing on dengue transmission, prevention and treatment (Suryanegara et al, 2017). But a study in Cambodia found no correlation between dengue fever knowledge and practice so a more comprehensive strategy is needed to change behavior (Kumaran et al, 2018).

A literature review conducted by Olliaro et al (2018) found that controlling the Aedes vector requires complex intervention. A community-based approach and the public sector will empower risk populations, reduce intervention costs, build sustainability, and increase the impact of vector control interventions. Likewise, the results of a study by Andersson et al (2017), informed community mobilization added effectiveness in controlling dengue fever.

The social and environmental context influences the development of risk behaviors for vector propagation at the household level (Causa et al, 2019). ). Containers around the house can be a potential place to breed Aedes mosquitoes. The most commonly found containers of larvae in research in Banten, Indonesia are concrete water storage tanks for bathrooms and water dispenser trays (Prasetyowati et al, 2018). Many people fail to recognize outdoor containers as mosquito breeding grounds (Sulistyawati et al, 2019).

A study conducted by Andersson et al (2015) on communities in Nicaragua and Mexico found that evidence-based community mobilization could increase the effectiveness of dengue vector control. Each site that implements the intervention in its own way has the advantage of local customization and strong community involvement.

Various programs and activities have been carried out to address the incidence of dengue in Medan, but an increase in dengue cases still occurs every year. This study aims to analyze the income, knowledge, attitudes and implementation of dengue prevention programs in Medan. The results of this study are expected to provide recommendations for developing strategies to improve the implementation of dengue prevention among the community, especially in the city of Medan.

\section{Research Method}

A face-to-face interview was conducted using a semi-structured questionnaire in July 2019. The respondent determined was the head of the household who had full authority to manage household needs. Only one person in one household surveyed. This cross-sectional study was carried out on 100 randomly selected heads of households that were administratively located in 3 sub-districts that had the top five persistent dengue endemicity in the last five years. Then from each sub-district selected 3 villages that have persistent dengue endemicity ranked in the top five in the last five years. So in total there are 9 villages and the number of respondents in each village office is determined proportionally based on the number of dengue cases in the last five years.

Data collection was carried out to explore income, knowledge, attitudes and implementation of dengue prevention. Knowledge related to dengue consists of 15 items with 4 answer choices including knowledge about the causes of dengue fever; knowledge of vectors, 
breeding places for mosquito larvae; knowledge of the 3M Plus program and symptoms of dengue fever.

Attitude consists of 7 items with a choice of answers strongly agree, agree, doubt, disagree, and disagree. The statement includes the participant's attitude towards activities that can support the prevention of dengue fever. Implementation of dengue prevention consists of 9 items with the choice of answers 'yes' and 'no' includes the implementation of 3M Plus.

Knowledge, attitude and implementation of dengue prevention were categorized as good and not good. The cut-off reaches more than $75 \%$ of the total score for good categories (Lugova and Wallis, 2017). Whereas for the descriptive purposes, it was divided into three categories, namely poor (score $<60 \%$ ), moderate (score $60-75 \%$ ), and good (score $>75 \%$ ).

Statistical analysis was performed with the Statistical Package for Social Sciences version 19. A $95 \%$ confidence level and a $\mathrm{p}$ value $<0.05$ were considered significant. Bivariate analysis using chi-square test, aims to determine the factors associated with the implementation of dengue prevention programs.

\section{Result and Discussion}

\subsection{Descriptive Analysis}

The majority of household heads who participated in this study were women (93\%). This shows that in general they manage household matters held by their wives or women even though they are also workers. Whereas men who manage household needs are those who work at home, while their wives work outside the home or those who are unemployed or have a wife who is sick for a long time.

Table 1. Distribution of respondents according to sociodemographic characteristics, knowledge, attitudes and implementation of dengue prevention

\begin{tabular}{lcc}
\hline \multicolumn{1}{c}{ Characteristics } & $\mathbf{n}$ & $\mathbf{0} \mathbf{0}$ \\
\hline Age & 51 & 51,0 \\
22-43 year & 49 & 49,0 \\
$\quad$ 44-72 year & 7 & 7,0 \\
Sex & 93 & 93,0 \\
$\quad$ Male & & \\
$\quad$ Female & 84 & 84,0 \\
Religion & 13 & 13,0 \\
$\quad$ Islam & 3 & 3,0 \\
$\quad$ Christian & & \\
$\quad$ Buddha & 19 & 19,0 \\
Education & 22 & 22,0 \\
$\quad$ Primary High School & 42 & 42,0 \\
$\quad$ Junior High School & 17 & 17,0 \\
$\quad$ Senior High School & & \\
$\quad$ College & 50 & 50,0 \\
Profession & 17 & 14,0 \\
$\quad$ Housewife & 13 & 13,0 \\
$\quad$ Entrepreneur & 10 & 10,0 \\
$\quad$ The trader &
\end{tabular}




$\begin{array}{lcc}\text { State Civil Apparatus } & 4 & 4,0 \\ \text { Employee } & 4 & 2,0 \\ \text { Teacher } & 2 & 2,0 \\ \text { Marital Status } & & \\ \quad \text { Married } & 89 & 89,0 \\ \quad \text { Un merried } & 11 & 11,0 \\ \text { Average monthly income } & & \\ \quad \text { Low (< Rp. 2.969.824) } & 61 & 61,0 \\ \quad \text { High }(>/=\text { Rp. } & 39 & 39,0 \\ \text { 2.969.824) } & & \\ \text { Knowledge } & & \\ \text { Poor } & 41 & 41,0 \\ \quad \text { Moderate } & 27 & 27,0 \\ \quad \text { Good } & 32 & 32,0 \\ \text { Attitude } & & \\ \quad \text { Poor } & 25 & 25,0 \\ \quad \text { Moderate } & 53 & 53,0 \\ \quad \text { Good } & 22 & 22,0 \\ \text { Implementation of dengue } \\ \text { prevention }\end{array}$

The age of respondents ranged from 22 to 72 years with an average age of 43 years. The highest level of education achieved by the majority of respondents was high school (42\%). The main occupation of the people surveyed was housewives $(50 \%)$. The majority of marital status was marriage $(89 \%)$.

The majority of household income is low or below Medan minimum wage IDR. 2,969,824 (61\%). This shows that the majority of households still live below the level of prosperity. The level of knowledge of the majority of respondents was at a poor level (41\%). The attitude of respondents was at a moderate level (53\%). While the implementation of dengue prevention was at a moderate level (39\%).

\subsection{Implementation of Dengue Prevention and Related Factors}

The results of the bivariate analysis showed that there was a significant positive relationship between household income and the implementation of dengue prevention $(p=<0.001)$. Good knowledge is more likely to implement dengue fever prevention well $(\mathrm{p}=0.012)$, and there was a significant positive relationship between attitude and implementation of dengue prevention ( $p$ $=<0.001)$.

Tabel 2. The relationship between income, knowledge and attitude with the implementation of dengue prevention

\begin{tabular}{|c|c|c|c|}
\hline \multirow[t]{2}{*}{ Independent variable } & \multicolumn{2}{|c|}{$\begin{array}{c}\text { Implementation of dengue } \\
\text { prevention }(\%)\end{array}$} & \multirow[t]{2}{*}{$\mathrm{p}$ value } \\
\hline & Not Good & Good & \\
\hline \multicolumn{4}{|l|}{ Income } \\
\hline Low & $55(55.0)$ & $6(6.0)$ & $<0.001$ \\
\hline High & $22(22.0)$ & $17(17.0)$ & \\
\hline
\end{tabular}


Knowledge

Not good

Good

$8(8.0)$

0.012

Attitude

Not good

68 (68.0)

$15(15.0)$

Good

$9(9.0)$

$10(10.0)$

$13(13.0)$

Low income or economic limitations are the most important barriers to controlling household level vectors. This is related to expenses for dengue prevention and mosquito control, including spending on waste collection services (Heydari et al, 2017). This finding is also similar to the study in Colombo which found a significant relationship between family income and dengue prevention practices (Chanyasanha et al, 2015). But these results differ from previous studies in the Philippines which did not find a significant relationship between income and dengue prevention practices (Lozano et al, 2018).

Our study found that households with high incomes have the ability to complete their home facilities such as wire screens on all windows and doors. They also have the ability to buy mosquito control products and prevent dengue fever such as mosquito coils, aerosol sprays, insect repellent, liquid insecticides, larvicides and equipment (mosquioto rackets and mosquito nets) and also the ability to pay for waste collection services.

Porcelain and plastic waste are more productive in urban areas. Household waste is related to Aedes sp productivity so that it can increase the risk of dengue epidemic. For this reason, appropriate steps are needed to limit the addition of waste to the environment (Banerjee et al, 2015). The amount of land around the house and the economic limitations to pay for garbage collection services, make households prefer to throw or burn trash in the front or back yard, and in a large field. Some households by the river even throw garbage into the river. The study in Colombo recommended implementation of waste collection that is appropriate and more user friendly and meets community requirements. Proper waste management will prevent the proliferation of dengue vector. Thus helping to manage dengue vectors (Udayanga et al, 2018).

We found that knowledge was positively related to dengue prevention practices. This finding is similar to previous research in Malaysia that knowledge is significantly and positively related to dengue prevention practices (Lugova and Wallis, 2017). This finding is also similar to the results of a household survey in urban areas in Yemen that knowledge is related to dengue prevention practices (Alyousefi, et al, 2016). And participants with high dengue knowledge have a higher level of involvement in dengue prevention practices (Wong et al, 2015).

The majority of respondents did not know the Aedes vector breeding grounds. They think the larvae transmitting dengue mosquitoes breed in ditches or dirty puddles. Likewise, most respondents did not know about the $3 \mathrm{M}$ Plus program. A small number of participants only knew about $3 \mathrm{M}$, and only 1 person knew what $3 \mathrm{M}$ Plus meant. Regarding the symptoms of dengue fever, there were some participants who did not know the typical symptoms of dengue fever. The majority of respondents stated fever, rash and bleeding as the main symptoms of dengue fever. Only a few participants knew the other main symptoms of dengue fever were muscle pain, abdominal pain, joint pain, and back pain.

We found that respondents who had good knowledge did not directly implement good dengue prevention either. Knowledge enhancement needs to be included in more 
comprehensive strategies for behavior change so that a high level of knowledge has a significant effect (Kumaran et al, 2018). The attitude of the majority of respondents was at a bad level. The majority of respondents gave a disagreeing statement to the statement to destroy trash around the house, sprinkle abate in water reservoirs, allow fogging inside the house, allow health workers to enter the house and check mosquito larvae. They stated that they would only clean the area that is part of their household because cleanliness must be the responsibility of each household. We also found that many participants did not agree to use insecticide sprays and products that produce smoke due to health problems. And also the people's assumption that mosquitoes mostly at night so they only use anti-mosquito products at night.

Some participants who received free larvaside by health workers did not put it in a water reservoir. They know its function but they are not sure of its effectiveness, they don't know how to use it and they are afraid it can affect their health. They are also afraid of the side effects of smoking, poisoning food, making the floors and walls dirty, and worrying about their effects on children. They consider that fogging is quite effective when done only outdoors, in trenches and in bushes. They believe that a house that is always cleaned will not have mosquitoes in it. They also do not want to accept health workers entering their homes for fear of being abused by others to commit crimes. This will hamper the implementation of dengue fever prevention programs properly.

\section{Conclusion}

Income, knowledge, and attitude related to the implementation of dengue prevention. Households with incomes below the city minimum wage must be the main target of the dengue prevention campaign. Knowledge and positive attitude lead to higher implementation of dengue prevention. Therefore a knowledge-based campaign and awareness rising will increase the implementation of dengue prevention. The Medan City Health Office needs to design a dengue prevention program based on local conditions and increase cross-sectoral collaboration to increase community acceptance of the program.

\section{References}

Alyousefi, T.A., Abdul-Ghani, R., Mahdy, M.A., Al-Eryani, S.M., Al-Mekhlafi, A.M., Raja, Y.A., Shah, S.A. and Beier, J.C., (2016). A household-based survey of knowledge, attitudes and practices towards dengue fever among local urban communities in Taiz Governorate, Yemen. BMC infectious diseases, 16(1), p.543.

Andersson, N., Nava-Aguilera, E., Arosteguí, J., Morales-Perez, A., Suazo-Laguna, H., LegorretaSoberanis, J., Hernandez-Alvarez, C., Fernandez-Salas, I., Paredes-Solís, S., Balmaseda, A. and Cortés-Guzmán, A.J., 2015. Evidence based community mobilization for dengue prevention in Nicaragua and Mexico (Camino Verde, the Green Way): cluster randomized controlled trial. Bmj, 351, p.h3267.

Andersson, N., Arostegui, J., Nava-Aguilera, E., Harris, E. and Ledogar, R.J., (2017). Camino Verde (The Green Way): Evidence-based community mobilisation for dengue control in Nicaragua and Mexico: feasibility study and study protocol for a randomised controlled trial. BMC Public Health, 17(1), p.407.

Banerjee, S., Aditya, G. and Saha, G.K., (2015). Household wastes as larval habitats of dengue vectors: comparison between urban and rural areas of Kolkata, India. PloS one, 10(10.

Causa, R., Luque-Fernandez, M.Á., Ochoa, H., Dor, A., Rodríguez, F.E.R.N.A.N.D.O., Solís, R.O.B.E.R.T.O. and Pacheco, A.L., (2019). Emerging arbovirosis (Dengue, Chikungunya, 
Zika) in the Southeastern Mexico: influence of social and environmental determinants on knowledge and practices. A mixed method study. BioRxiv, p.581603.

Chanyasanha, C., Guruge, G. R., \& Sujirarat, D., (2015). Factors influencing preventive behaviors for dengue infection among housewives in Colombo, Sri Lanka. Asia Pacific Journal of Public Health, 27(1), 96-104.

Heydari, N., Larsen, D., Neira, M., Beltrán Ayala, E., Fernandez, P., Adrian, J., Rochford, R. and Stewart-Ibarra, A., (2017). Household dengue prevention interventions, expenditures, and barriers to Aedes aegypti control in Machala, Ecuador. International journal of environmental research and public health, 14(2), p.196.

Johansen, I. C., do Carmo, R. L., Correia Alves, L., \& Bueno, M. D. C. D., (2018). Environmental and demographic determinants of dengue incidence in Brazil. Revista de Salud Pública, 20, 346-351.

Kumaran, E., Doum, D., Keo, V., Sokha, L., Sam, B., Chan, V., Alexander, N., Bradley, J., Liverani, M., Prasetyo, D.B. and Rachmat, A., (2018). Dengue knowledge, attitudes and practices and their impact on community-based vector control in rural Cambodia. PLoS neglected tropical diseases, 12(2), p.e0006268.

Lozano, E. B., Isok, B. T., \& Greif, M. M., (2018). People's knowledge, attitude and practices on dengue in two barangays with high dengue incidences in Cebu city, Philippines. Journal of Entomology and Zoology Studies 2018; 6(3): 218-223.

Lugova, H. and Wallis, S., (2017). Cross-sectional survey on the dengue knowledge, attitudes and preventive practices among students and staff of a public university in Malaysia. Journal of com munity health, 42(2), pp.413-420.

Ministry of Health of the Republic of Indonesia. (2015). Rencana Strategis Kementerian Kesehatan Tahun (2015-2019). Jakarta: Sekretariat Jenderal Kemenkes RI.

Ministry of Health of the Republic of Indonesia. (2016). Surat Edaran Nomor PM.01.11 / Menkes / 591/2016 tentang Pelaksanaan Pemberantasan Sarang Nyamuk 3M Plus dengan Gerakan Satu Rumah Satu Jumantik. Jakarta: Kementerian Kesehatan Republik Indonesia.

Ministry of Health of the Republic of Indonesia. (2018). Data dan Informasi. Profil Kesehatan Indonesia (2017). Jakarta: Kementerian Kesehatan Republik Indonesia.

North Sumatra Province Health Office, (2018). North Sumatra Province Health Profile 2017. Medan: North Sumatra Province Health Office.

Olliaro, P., Fouque, F., Kroeger, A., Bowman, L., Velayudhan, R., Santelli, A.C., Garcia, D., Ramm, R.S., Sulaiman, L.H., Tejeda, G.S. and Morales, F.C., (2018). Improved tools and strategies for the prevention and control of arboviral diseases: A research-to-policy forum. PLoS neglected tropical diseases, 12(2), p.e0005967.

Prasetyowati, H., Ipa, M. and Widawati, M., (2018). Pre-Adult Survey to Identify the Key Container Habitat of Aedes Aegypti (L.) In Dengue Endemic Areas of Banten Province, Indonesia. Southeast Asian Journal of Tropical Medicine and Public Health, 49(1), pp.23-31.

Suryanegara, F.D.A., Setyaningrum, N., Suparmi, S., Triaji, A., Wibowo, M.R. and Ransatullah, M.Y., (2017), October. People's Knowledge on Dengue Hemorrhagic Fever. In Health Science International Conference (HSIC 2017). Atlantis Press.

Udayanga, L., Gunathilaka, N., Iqbal, M.C.M., Lakmal, K., Amarasinghe, U.S. and Abeyewickreme, W., (2018). Comprehensive evaluation of demographic, socio-economic and other associated risk factors affecting the occurrence of dengue incidence among Colombo and Kandy Districts of Sri Lanka: a cross-sectional study. Parasites \& vectors, 11(1), p.478.

WHO, (2012). Global Strategy for Dengue Prevention and Control 2012-2020. WHO Library Cataloguing-in-Publication Data, Switzerland.

WHO, 2016. New handbook for dengue outbreak contingency planning [Internet]. Available: https://www.who.int/tdr/news/2016/handbook-dengue-outbreak/en. 